\title{
DESIGN AND EFFICIENCY OF A SMALL-SCALE WOODCHIP FURNACE
}

\author{
Carlos Torres-Fuchslocher ${ }^{1, \wedge}$, Felipe Varas-Concha ${ }^{1,2}$
}

\begin{abstract}
Although advances have been made in combustion efficiency in large-scale woodchip furnaces, less experimental results are available at the $<20 \mathrm{~kW}$ range. Compact feed systems, as well as optimized grates and combustor chambers, continue to represent a challenge for the wider use of low-cost wood chips. This study describes the design and testing of a small-scale woodchip furnace that operates at a range of 9-18 kW. The efficiency test takes account of the feedstock Eucalyptus nitens, with three moisture contents and the combination of different air excess $(\lambda)$ and primary/secondary air ratios. The results reveal a maximum of combustion efficiency of $85 \%$ for the low moisture content sample $(16 \%)$ at $\lambda=1,5$ and $82 \%$ for samples with $29 \%$ and $40 \%$ moisture content, at $\lambda=2,0$ and 2,1 respectively. The integrated heat exchanger proved to be highly efficient by reducing gas temperature by up to $69 \%$ prior to its exit.
\end{abstract}

Keywords: Combustion efficiency, fixed grate, hearth appliances, stove design, wood chips.

\section{INTRODUCTION}

\section{Wood chips as fuel for small furnaces}

Combustion efficiency is the main output variable describing the performance of a biomass furnace (Nussbaumer and Good 1998). FNR (2007) shows a list of boilers and heating devices that reach up to $92,9 \%$ efficiency when dry ( $20 \%$ moisture) wood chips are used as fuel. The efficiency decreases until $82 \%$ when $32,5 \%$ moisture fuel is used. Although advances have been made in efficiency in large-scale woodchip furnaces, less experimental results are available at the $<20 \mathrm{~kW}$ range (Gaegauf and Salerno 1991, Bühler 1992). Ramakers et al. (2004) show experimental results from wood/sand fluidization as a way to extend the use high moisture woodchips.

Most recent research has focused on particulate matter emission and pellets stove performance (Wiinikka and Gebart 2004, Persson et al. 2008, Johansson et al. 2003, Eskilson et al. 2004, Soto and Núñez 2008). However, compact feed systems development, as well as grates and combustion chambers improvement, continue to represent a challenge for the wider use of low-cost wood chips.

Wood-based heating is still dominated by the use of logs, although there has been a strong increase in the market share of pellets in recent years, particularly in the central heating sector. The strong position held by log wood-based devices presents an opportunity for introducing more efficient alternatives (ADEME 2011, Audigane et al. 2012).

\footnotetext{
1 Facultad de Ingeniería, Universidad de Talca, Talca, Chile.

2 Pontificia Universidad Católica, Santiago, Chile

^ Corresponding author: catorres@utalca.cl

Received: 22.01.2014 Accepted: 21.07.2014
} 
The main advantage of using wood chips as a fuel, as opposed to logs and pellets, relates to price. Wood chips have a worldwide market, given that they are primarily used in the production of wood panels and cellulose. They are traded as a commodity at a price of approximately US $\$ 14$ per cubic meter. Alternatively, logs and pellets, depending on local market conditions, might reach three to five times this cost respectively (Own market research. A comparison of energy content). However, in contrast to pellets, wood chips are not usually available as ready-to-use fuel for small devices due to their irregular size and high moisture content. Nonetheless, considering Nussbaumer's (2003) statement that, in fact, direct combustion can be applied to biomass of up to $60 \%$ water content, a number of significant questions arise: Can an acceptable efficiency be achieved in small furnaces? What are the design specifications that would make this possible?

This study proposes a new design for woodchip stoves. In addition, an efficiency test is then conducted to determine the performance of the device under different conditions of moisture, air excess and primary-secondary air ratio.

\section{Design of the stove}

The proposed stove is intended to serve as a stand-alone heating device. The external cylindrical body has a diameter of $50 \mathrm{~cm}$ and a height of $50 \mathrm{~cm}$. It has inside two cylindrical combustion chambers. The secondary chamber is located above the primary and it is surrounded by a refractory wall that has an internal diameter of $30 \mathrm{~cm}$ and a height of $42 \mathrm{~cm}$ (Figure 1 $\mathrm{c}$ and Figure 2). Two plates located between the two chambers divide the space and serve as a diffusor for the secondary air supply (Figure $1 \mathrm{~d}$ and Figure 2). The volume ratio between chamber one and chamber two is 2:3.

The fixed grate is formed by three concentric units that form a quasi-conic shape. This connects to a common chamber underneath, from which the primary air supply is provided. As a result, the grate is able to provide a staging primary air supply. Secondary air inflow is located one meter above the furnace and uses a duct with a $5 \mathrm{~cm}$ diameter, placed concentrically inside the exhaust gas duct. This two-duct array serves as a recovery heat device, preheating the secondary air before it enters through the diffusing plates into the combustion chamber. The primary air and the secondary air are supplied by separate fans.

The fuel storage is located under the combustion chamber and is equipped with a centrally-located vertical auger. This feeds the wood chips into the first chamber, in the middle of the grate.

The fed wood chips build a pile above the grate. They maintain a low temperature due to the newly inflowing fuel. The flame front is built above the pile, where higher temperatures are generated.

Once the flue gas exits the secondary chamber, it flows into a cavity between the chamber's wall and the stove's external layer. This cavity is fitted with vertically crossing tubes that act as a heat exchanger (Figure 1b). Room air flows by natural convection through the tubes, while the exhaust gas flows to the duct. 


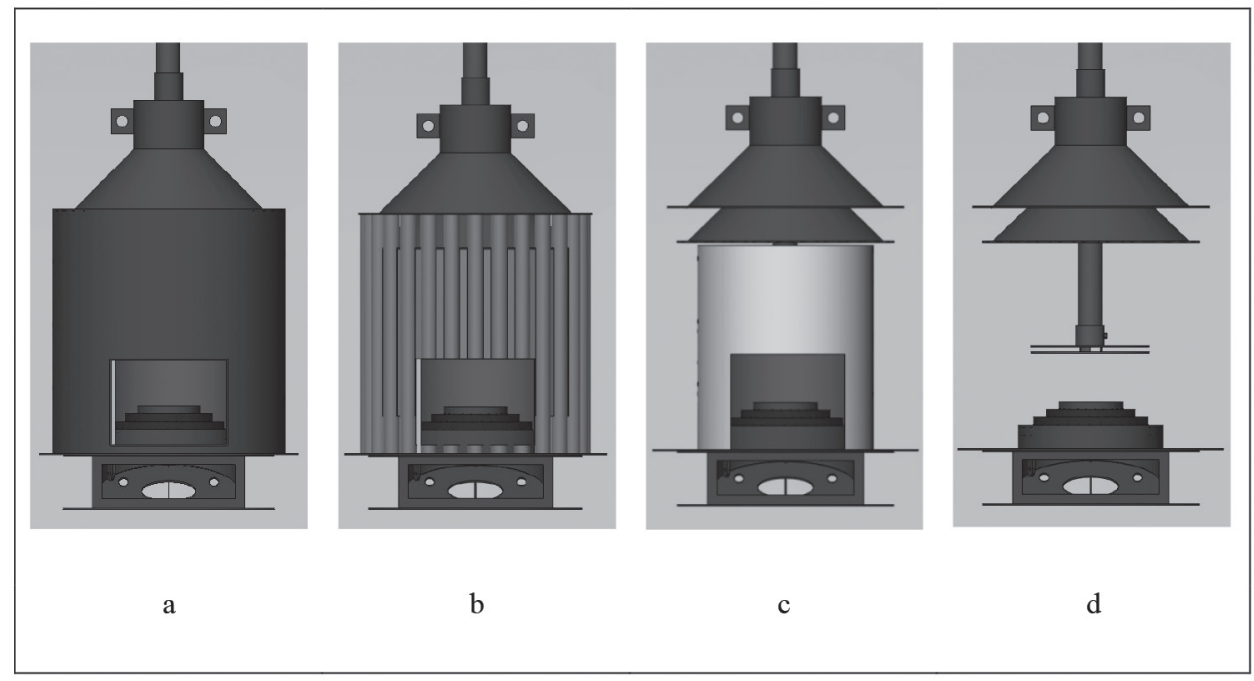

Figure 1. Prototype of woodchip stove.

\section{MATERIALS AND METHOD}

The prototype of the stove was built and installed in the laboratory and it was equipped to conduct gas analysis as well as to measure the design's performance.

The entire furnace and hopper were mounted on floating load cells, which enabled the fuel input's mass to be registered. Given that the main purpose of the furnace is to serve as a hearth appliance, its performance was estimated in terms of the simplified formula of combustion efficiency $(\eta)$, as suggested by Nussbaumer and Good (1998).

$$
\eta=100-V_{\text {therm }}-V_{\text {chem }}[\%]
$$

where

$V_{\text {therm }}=$ thermal losses of the flue gas or stack loss [\%]

$V_{\text {chem }}=$ chemical losses of the flue gas [\%]

The stack loss $V_{\text {therm }}$ was calculated directly with the gas analyzer, using the Siegert formula and the registered $\left(\mathrm{CO}_{2}\right)$ carbon dioxide measured in [vol.-\%].

$$
V_{\text {therm }}=f \frac{T_{a}-T_{u}}{\mathrm{CO}_{2}}
$$

where $T_{a}$ was the temperature of the flue gas $\left[{ }^{\circ} \mathrm{C}\right], T_{u}$ was the ambient temperature $\left[{ }^{\circ} \mathrm{C}\right], \mathrm{CO}_{2}$ the value read by an infrared sensor [vol.- $\%]$, and $\mathrm{f}$ the fuel-specific factor $\left[\% /{ }^{\circ} \mathrm{C}\right]$. 
The chemical losses caused by incomplete combustion $V_{\text {chem }}$ were estimated by equation 3 . Nussbaumer and Good (1998) and Good and Nussbaumer (1993) for detailed derivation of equation 3.

$$
V_{\text {chem }}=\frac{C O 11,800}{C O_{2}+C O \frac{h_{u \text { atro }}}{100}-0,25 u}[\%],
$$

Where $h_{\text {uatro }}=$ heating value of dry wood $=18,500\left[\mathrm{~kJ} \mathrm{~kg}^{-1}\right]$

$\mathrm{CO}$ : carbon monoxide [vol.-\%]

$\mathrm{CO}_{2}$ : carbon dioxide [vol.-\%]

The feedstock used for testing was Eucalyptus nitens, which is a common byproduct of the timber industry and the raw material for wood board and other wood-based products. Proximate analysis was conducted before testing using the methods outlined in table 1 .

Table 1. Physical and thermal properties of feedstock wood (Eucalyptus nitens).

\begin{tabular}{llc}
\hline \multicolumn{1}{c}{ Analysis } & \multicolumn{1}{c}{ Method } & $\begin{array}{c}\text { Eucalyptus } \\
\text { nitens }\end{array}$ \\
\hline Moisture content $(\% \mathrm{wb})$ & Oven method - AOAC* official method 945,15 & 21,85 \\
Ash content $(\% \mathrm{db})$ & Muffle - AOAC official method 940,26 & 1,34 \\
Row fiber $(\% \mathrm{db})$ & Gravimetric method - AOAC official method 920,169 & 96,37 \\
Protein $(\% \mathrm{db})$ & Kjeldahl method - AOAC official method 979,09 & 1,30 \\
Oil content $(\% \mathrm{db})$ & Soxhlet method - AOAC official method 963,15 & 1,08 \\
Density $\left(\mathrm{gr} / \mathrm{cm}^{3}\right)$ & Direct measurement & 1,084 \\
\hline
\end{tabular}

*Association of Official Analytical Chemists.

Source: Measurements conducted at own laboratory.

As one of the main issues addressed by the new design is the burning of high moisture wood chips, Table 2 shows the lower heating value of three samples of Eucalyptus nitens used for the tests: low moisture (LM:16,35\%), medium moisture (MM:29,25\%) and high moisture content (HM:40,27\%). The lower heating value was measured with a digital bomb calorimeter.

Table 2. Moisture content of samples.

\begin{tabular}{lcc}
\hline $\begin{array}{c}\text { Sample } \\
\text { (moisture content } \% \mathrm{wb})\end{array}$ & Method & $\begin{array}{c}\text { Lower heating } \\
\text { value } \\
(\mathrm{kWh} / \mathrm{kg})\end{array}$ \\
\hline LM $(16,35)$ & Oven method - AOAC official method 945,15 & 4,65 \\
MM $(29,25)$ & Oven method - AOAC official method 945,15 & 3,86 \\
HM $(40,27)$ & Oven method - AOAC official method 945,15 & 3,20 \\
\hline
\end{tabular}

For each sample, 15 tests were carried out by varying the fuel feed rate $\left(f_{i}\right)$ and air supply - measured as air excess $\left(\lambda_{i}\right)$. As part of each test, the ratio between primary air and secondary air was alternated by completing 12 combinations of A1/A2 ratio (Primary air flow divided by secondary air flow [dimensionless].). A stabilization time between observation units was considered.

A total of 7 sample points were determined for measuring temperature. Figure 2 indicates the location of these points and the flow of gases inside the stove. Points 1 and 2 were located in the primary chamber, just above the pile flame and below the dividing plates. Points 3 and 4 were located inside the secondary chamber, above the dividing plates. Points 5 and 6 were located at the beginning and the end of the heat exchanger. The temperature of point 7 corresponds to the flue gas flowing through the duct, next to the gas sample point. 
Gas testing was carried out using a Testo 350-XL gas analyzer, which was equipped with an infrared $\mathrm{CO}_{2}$ sensor for direct measurement of this gas. The temperature was measured by custom-made thermocouples. These were calibrated using the calibration unit Fluke 724.

The effect of input variables on $C O$ and combustion efficiency output variables was examined using quadrant analysis, as a way of detecting the best performance points (regarding $C O$ and efficiency). The distribution of average temperatures inside the chambers, heat exchanger and duct are shown for the three moisture contents. The means values are compared by one-way analysis of variance and Tukey's method for pairwise comparisons (95\% confidence level) using the statistical software Minitab 16 . The relationship of efficiency and air excess ratio is represented in a graph which tracks the three samples.

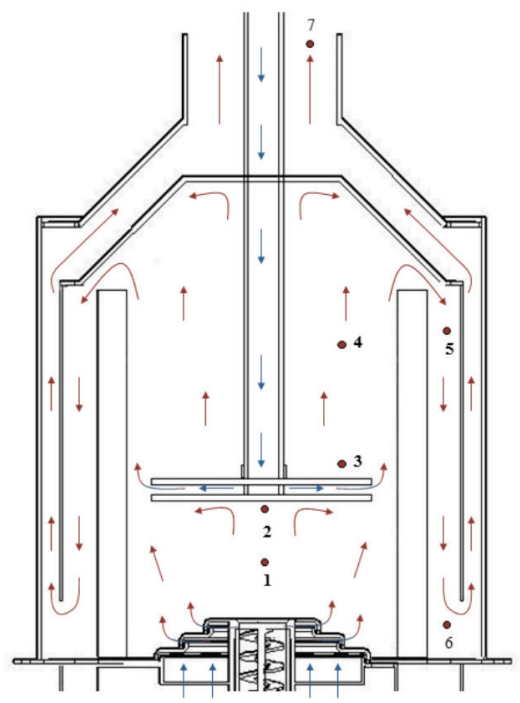

Figure 2. Flue gas flow inside the furnace and location of temperature sampling points.

\section{RESULTS AND DISCUSSION}

The main output variables measured during the tests were: temperature profile $\left[{ }^{\circ} \mathrm{C}\right]$, combustion efficiency [\%] and $\mathrm{CO}$ emissions [ppm]. These variables have been used to detect the best operational conditions.

Figure 3 shows different temperature profiles according to fuel moisture content and the point of measurement along the flue gas stream (Average temperatures considering all observations.). The burning of low moisture wood chips produced the highest temperature profile, reaching a maximum of $793^{\circ} \mathrm{C}$ $( \pm 4,0 \%)$ at point 4 in the secondary chamber, and $242^{\circ} \mathrm{C}( \pm 3,4 \%)$ at the exit duct. On the other hand, the burning of high moisture wood chips resulted in a maximum temperature of $637^{\circ} \mathrm{C}( \pm 3,6 \%)$, and $194^{\circ} \mathrm{C}( \pm 3,4 \%)$ at the exit duct. This means that combustion temperature varies by $26 \%$, depending on the moisture content. The one-way analysis of variance and Turkey's method proved that there were statistically significant differences between the means values of temperature for each test except for point 6 , where there was no significant difference between medium and high moisture content ( It is worth highlighting that higher temperature could be found in other points not included in the test). 
Only low moisture wood chips presented higher temperatures in the secondary chamber compared to the primary chamber. This might be consequence of gasification predominance resulting from low temperature in the primary chamber and subsequently superior availability of fuel as gas at the secondary chamber.

The temperature drop between point 4 and point 7 demonstrates the solid performance of the heat exchanger. Here, exhaust gas temperature was reduced by $69 \%$ prior to the exit of low moisture probes, and by $67 \%$ for high moisture probes.

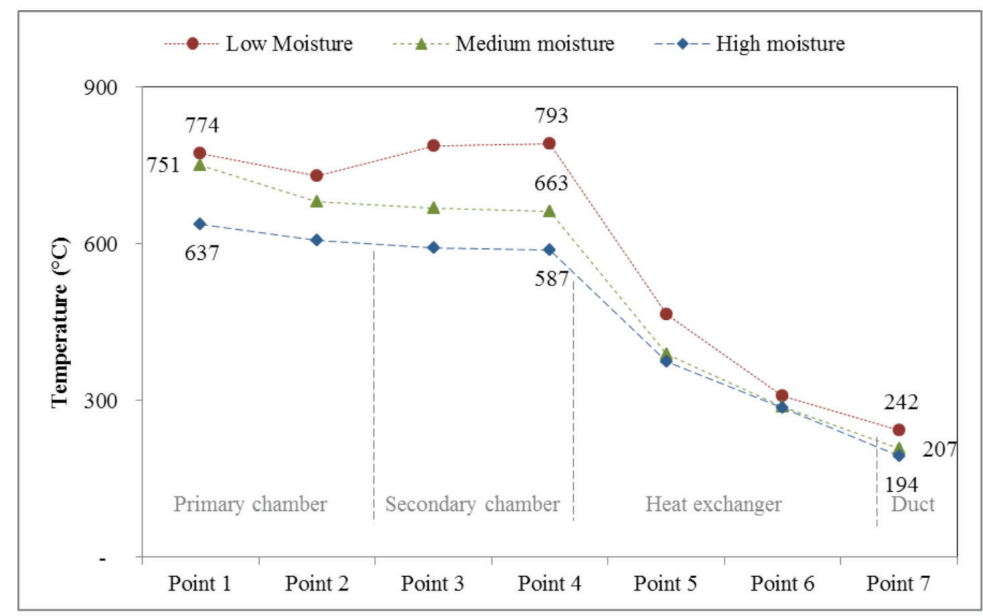

Figure 3. Temperature at different stages according to three fuel moisture contents.

Combustion efficiency was tested for the three fuel moisture contents using different air excess and A1/A2 ratios. A fourth grade polynomial adjustment for each one was chosen to represent efficiency $\eta$ vs. air excess ratio $\lambda$ (Figure 4 ). The resulting functions and coefficient of determination $\left(\mathrm{R}^{2}\right)$ are as follows:

$$
\begin{aligned}
& \eta_{\text {LM }}=-0,218 \lambda^{4}+3,0812 \lambda^{3}-15,67 \lambda^{2}+29,425 \lambda+67,098 \quad\left(\mathrm{R}^{2}=0,9507\right) \\
& \eta_{\text {MM }}=0,0059 \lambda^{4}-0,0337 \lambda^{3}-0,9247 \lambda^{2}+3,9575 \lambda+78,095 \quad\left(\mathrm{R}^{2}=0,8999\right) \\
& \eta_{\text {HM }}=0,0145 \lambda^{4}-0,0755 \lambda^{3}-0,9923 \lambda^{2}+4,6775 \lambda+76,507 \quad\left(\mathrm{R}^{2}=0,7590\right)
\end{aligned}
$$

The three lines show combustion efficiency peaks in an expected range. In the case of the LM, a maximum of $\eta=85,3 \%$ was reached at $\lambda=1,53$; for $\mathrm{MM} \eta=82,1 \%$ it was found at $\lambda=2,02$; and for HM $\eta=81,5 \%$ at $\lambda=2,12$. The decrease of $3,7 \%$ in combustion efficiency, when comparing the cases of low and high moisture content, demonstrates the effectiveness of the stove design in terms of burning high moisture wood chips. However, high moisture burning requires an increase of $39 \%$ in $\lambda$, which reduces the temperature and produces higher levels of particulate matter. The expected combustion efficiency with stoichiometric air supply $(\lambda=1)$ is $83,7 \% ; 81,1 \%$ and $80,1 \%$ by low, medium and high moisture content respectively. 


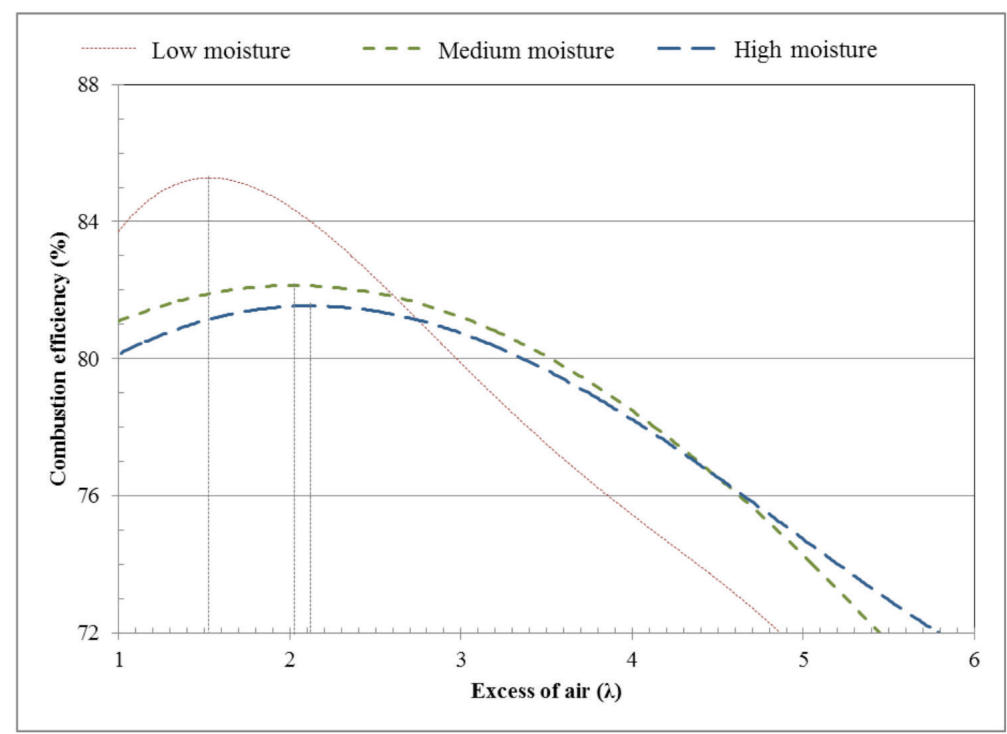

Figure 4. Combustion efficiency at different moisture contents versus excess air ratio - polynomial adjustment.

A quadrant analysis was used in order to detect the best operational conditions regarding combustion efficiency and $\mathrm{CO}$ emissions measured in [ppm], for all three moisture contents. The objective was to identify the A1/A2 ratio that minimized $C O$ emissions, but also maximized efficiency. Figure 5, 6, 7 show the average results for wood chips with low, medium and high moisture content respectively. Each chart consists of 12 points representing every possible A1/A2 ratio. These were produced from a combination of three possible operational levels for primary air supply $(1,2,3)$, and four for secondary air supply ( 0 , $1,2,3)$. The excess air ratio was measured for every possible A1/A2 ratio. The three levels of primary air are represented by the series given in each chart, where each of them shows the levels of secondary air.

The best operational conditions regarding A1/A2 and $\lambda$ in the LM case are 2:1 $(\lambda=2,8)$ and $2: 3(\lambda=2,7)$, in MM are 2:0 $(\lambda=3,1)$ and 3:1 $(\lambda=3,6)$, and in HM are 3:2 $(\lambda=3,9)$ and 2:1 $(\lambda=3,6)$. Results show that the dominant air may be either primary or secondary by LM, but by MM and HM the best performance points correspond to primary air dominance. This can be explained by the lower registered temperatures, which prevent secondary air effectiveness (Figure 3). On the other hand, it validates the performance of the primary air staging system, including in the grate. 


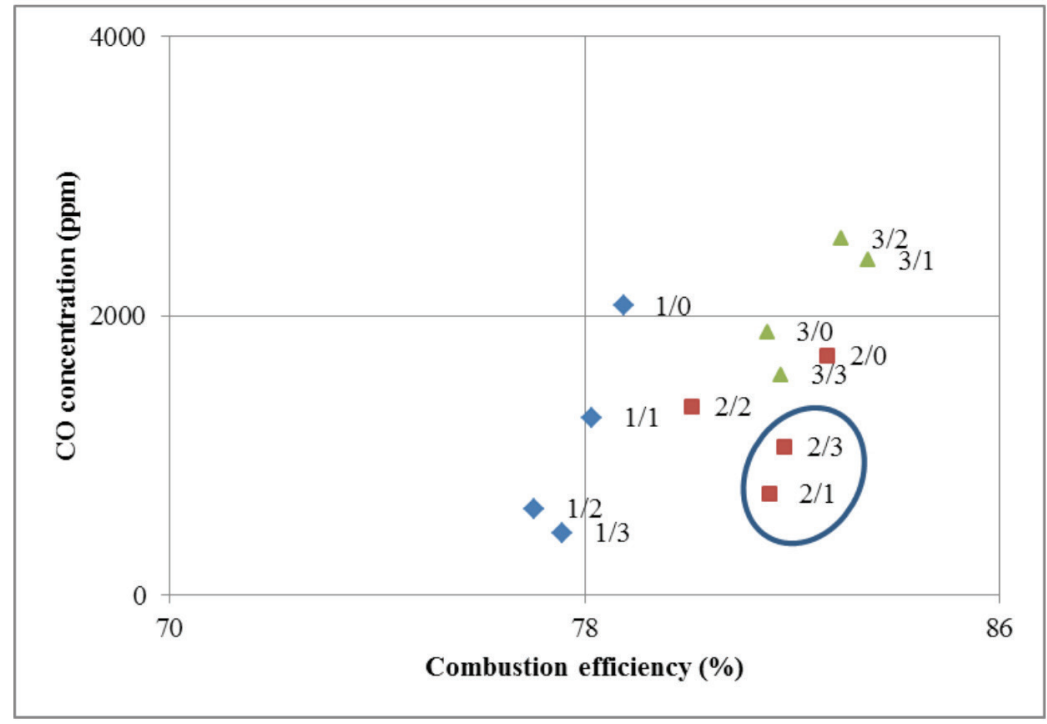

Figure 5. $C O$ concentration (ppm) and combustion efficiency for different $\lambda$ and $A 1 / A 2$ ratios. Moisture content LM (16,35\%).

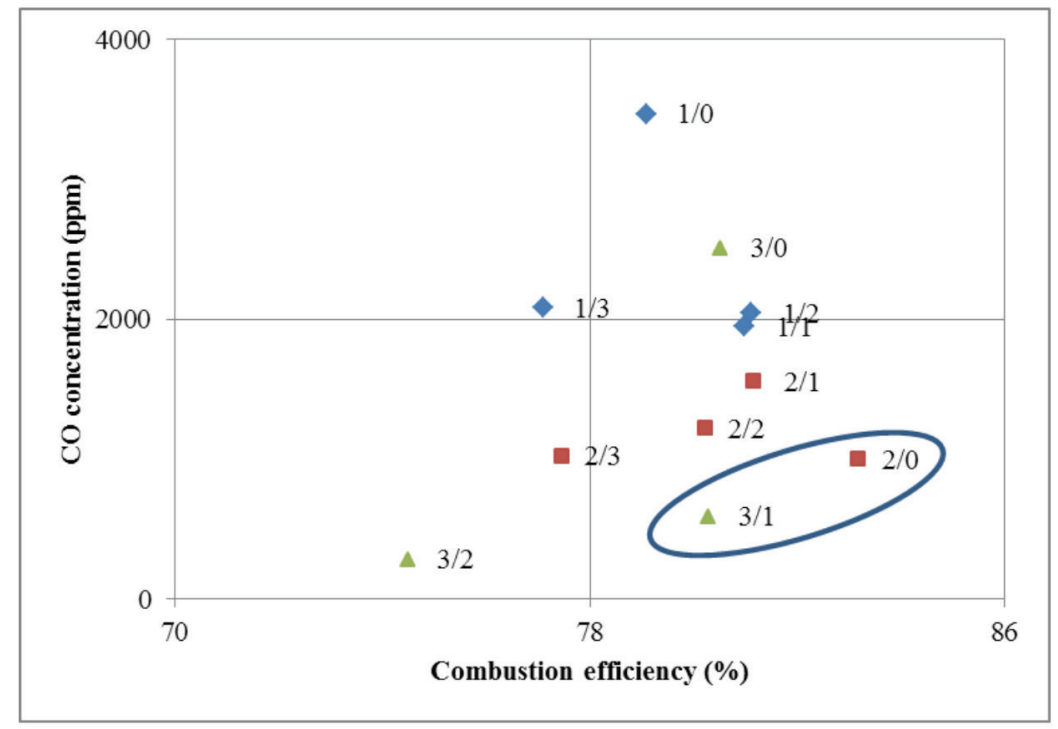

Figure 6. $C O$ concentration (ppm) and combustion efficiency for different $\lambda$ and A1/A2 ratios. Moisture content MM (29,25\%). 


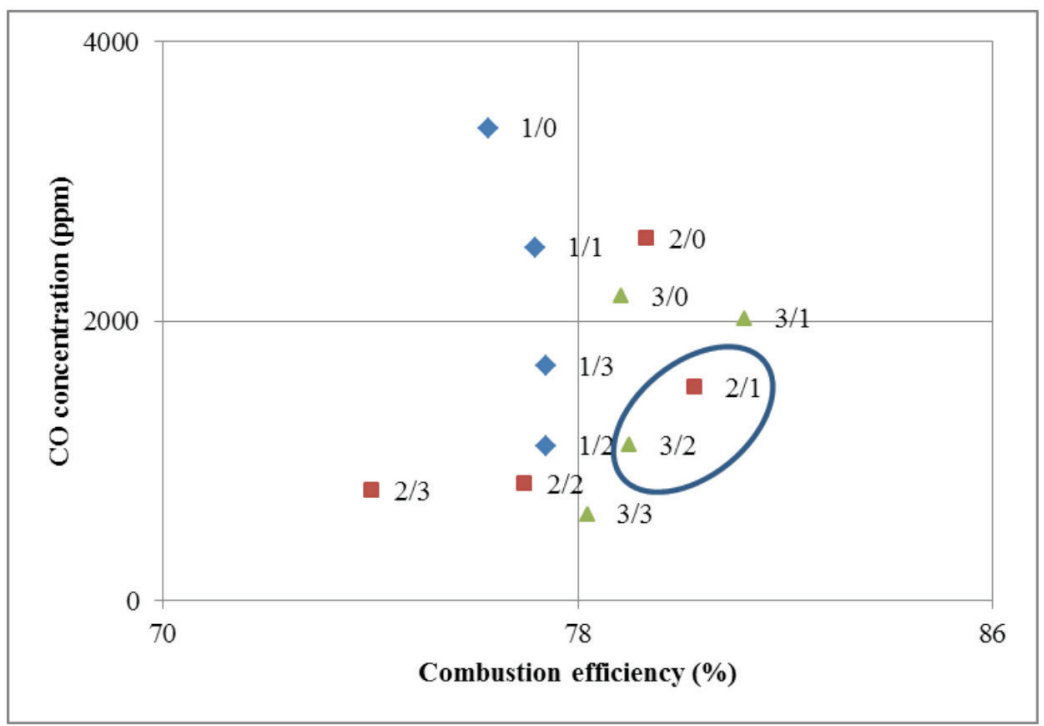

Figure 7. $C O$ concentration (ppm) and combustion efficiency for different $\lambda$ and $\mathrm{A} 1 / \mathrm{A} 2$ ratios. Moisture content HM (40,27\%).

\section{CONCLUSIONS}

This study fills the gap on experimental data concerning small-scale furnaces, and, in particular, wood chips burning devices. A new patented furnace design has been proposed and tested. The effect of input variables (moisture content, air excess ratio and primary/secondary air ratio) on output variables (temperature, carbon monoxide and combustion efficiency) has been quantified and analyzed using a series of charts.

The peaks in combustion efficiency found in this research are as expected in terms of fuel with low moisture content. However, it is slightly greater $(3,1 \%)$ than the cases of medium and high moisture content $(4,3 \%)$. This verifies the effectiveness of the stove's design in terms of burning high moisture wood chips. According to FNR (2007) other larger devices available at the market show $82 \%$ efficiency when $32,5 \%$ moisture content chips are used which is comparable with the $81,5 \%$ obtained by the test with 40,27 moisture content.

The heat exchanger also proved to be effective, by reducing the exhaust gas temperature by up to $69 \%$ before its exit.

Results also show that the dominant air may be either primary or secondary by LM, but by MM and $\mathrm{HM}$ the best performance points correspond to primary air dominance. This suggests that the primary air staging system, as well as the grate used for high moisture content burning, perform solidly.

\section{ACKNOWLEDGEMENTS}

The authors thank CONICYT- FONDEF, I Concurso IDeA Ciencia Aplicada (CA12I10235) for providing the funds to carry out this research. 


\section{REFERENCES}

ADEME. 2011. Directory of the French Wood Heating Industry. French Industry Report. Retrieved [December 3, 2013].

Audigane, N.; Bentele, M.; Ferreira, J.; Gyurik, Á.; Jossart, J.; Mangel, A.; Martin, M.; Masdemont, P.; Mörner, H.; Paniz, A.; Pieret, N.; Rechberger, P.; Rakos, C.; Schlagitweit, C.; Sievers, A.; Tuohiniitty, H. 2012. European Pellet Report 2012. Report for Pellcert. Retrieved [October $13,2013]$.

Bühler, R. 1992. Ringversuche zur Typenprüfung von Holzheizkesseln. Bundesamt für Energiewirtschaft, report, Bern.

FNR 2007. Marktübersicht Hackschnitzel-Heizungen. Fachagentur Nachwachsende Rohstoffe e.V. Retrieved [December 17, 2013].

Eskilson, D.; Rönnbäck, M.; Samuelson, J.; Tullin, C. 2004. Optimisation of efficiency and emissions in pellet burners. Biomass and Bioenergy 27 (6): 541-546.

Gaegauf, Ch.; Salerno, B. 1991. Das Abbrandverhalten von Klein-Holzfeuerungen. Bundesamt für Energiewirtschaft, ENET, Bern.

Good, J.; Nussbaumer, Th. 1993. Wirkungsgradbestimmung bei Holzfeuerungen, Bundesamt für Energiewirtschaft, ENET, Bern.

Johansson, L.; Tullin, C.; Leckner, B.; Sjövall, P. 2003. Particle emissions from biomass combustion in small combustors. Biomass and Bioenergy 25 (4): 435-446.

Nussbaumer, Th.; Good, J. 1998. Determination of the combustion efficiency in biomass furnaces. Proceedings $10^{\text {th }}$ European conference and technology Exhibition biomass for energy, industry and climate protection. Würzburg.

Persson, T.; Fiedler, F.; Nordlander, S.; Bales, C.; Paavilainen, J. 2008. Validation of a dynamic model for wood pellet boilers and stoves. Applied Energy 86 (5): 645-656.

Ramakers, B.; de Ridder, R.; Kerkhof, P. 2004. Fluidization behavior of wood/sand mixtures. Maderas. Ciencia y Tecnología 6(2): 145-153.

Soto, G.; Núñez, M. 2008. Fabricación de pellets de carbonilla, usando aserrín de pinus radiata (D. Don), como material aglomerante. Maderas. Ciencia y Tecnología 10(2): 129-137.

Wiinikka, H.; Gebart, R. 2004. Experimental investigations of the influence from different operating conditions on the particle emissions from a small-scale pellets combustor. Biomass and Bioenergy 27 (6): 645-652. 